\title{
NUMERYCZNE WYZNACZANIE STOPNIA ZMIESZANIA WODY I KAOLINU W MIESZALNIKU STATYCZNYM
}

\begin{abstract}
Jednym z elementów przemysłowego procesu oczyszczania wody lub ścieków jest flokulacja, jako proces tworzenia agregatów z cząstek fazy stałej, będącej wynikiem oddziaływania i wiązania powierzchni agregatów za pośrednictwem zaadsorbowanego na nich związku polimerowego. Powstałe ciężkie i porowate agregaty zwane flokułami zaczynają poddawać się siłom grawitacji i są łatwe w filtracji. Proces flokulacji jest inicjowany przez wprowadzenie cząstek stałych, np. kaolinu, które powinny być rozprowadzone równomiernie w fazie ciekłej. Przy zastosowaniu mieszalnika statycznego są one wprowadzane do rurociągu instalacji wodnej lub ściekowej bezpośrednio przed mieszalnikiem. Konstrukcja mieszalnika ma zapewnić pełne i równomierne zmieszanie cząstek stałych z cieczą. W niniejszej pracy pokazano numeryczne wyznaczenie stopnia zmieszania wody i kaolinu w mieszalniku statycznym za pomocą CFD oraz ocenę jego działania w kontekście skuteczności mieszania oraz zdatności w warunkach przemysłowych. Symulacja nieustalonego procesu mieszania pozwala zamodelować zachowanie się cząstek fazy stałej na całej długości mieszalnika i w efekcie daje możliwość określenia optymalnych wymiarów mieszalnika, takich jak m. in. jego długość oraz ilość przegród zaburzających. Mieszalnik ten może być wykorzystywany $\mathrm{m}$. in. we wstępnych fazach oczyszczania ścieków albo w procesach produkcji zawiesin.
\end{abstract}

Słowa kluczowe: flokulacja, zawiesiny, mieszanie, przepływ dwufazowy, symulacja CFD, optymalizacja

\section{Wstęp}

Mieszanie jest jednym z najważniejszych procesów zachodzących w przemyśle chemicznym, wykorzystywanym m. in. w procesie flokulacji [6]. Mie-

\footnotetext{
${ }^{1}$ Autor do korespondencji: Ryszard Kantor, Politechnika Krakowska, ul, Warszawska 24, 31-155 Kraków, 1262835 85, rkantor@mech.pk.edu.pl.

2 Mateusz Majoch, FAKRO PP Sp. z o.o., ul. Węgierska 144a, 33-300 Nowy Sącz, mateuszmajochns@gmail.com.
} 
szanie może zachodzić w sposób samorzutny, lub wymuszony po doprowadzeniu do układu energii mechanicznej w urządzeniach zwanych mieszalnikami.

Obecnie istnieje wiele odmian konstrukcyjnych mieszalników. Do najbardziej rozpowszechnionych należą mieszalniki przepływowe, powszechnie zwane mieszalnikami statycznymi, ze względu na brak ruchomych elementów. Proces mieszania $\mathrm{w}$ mieszalnikach statycznych polega na zaburzeniu przepływu mieszaniny poprzez zmiany jego kierunku, prędkości oraz generację wirów burzliwych. Wadą mieszalników statycznych są często znaczące opory przepływu, stąd istnieje zapotrzebowanie na optymalizację ich konstrukcji w kierunku zmniejszenia spadków ciśnienia podczas przepływu płynu przez mieszalnik. Modelowanie CFD znacząco skraca i upraszcza proces projektowania i optymalizacji konstrukcji mieszalnika.

W niniejszej pracy zaprezentowano symulację CFD ustaloną i nieustaloną procesu mieszania ziaren kaolinu $\mathrm{z}$ wodą $\mathrm{w}$ mieszalniku statycznym pokazanym na rysunku Rys. 1, wykorzystywanym w m. in. procesach flokulacji. Do symulacji przyjęto następujące założenia [4]:

- mieszalnik w kształcie zasadniczo rury z odpowiednio rozmieszczonymi i ukształtowanymi przegrodami połówkowymi z linią w układzie pionowym,

- średnica wewnętrzna $(d)$ mieszalnika $36 \mathrm{~mm}$,

- długości strefy mieszania mieszalnika $0,5 \mathrm{~m}$,

- odległość pomiędzy przegrodami połówkowymi jest równa $2 d$,

- udział masowy kaolinu w wodzie: 0.005,

- materiał mieszalnika: PCV, wysokość chropowatości 0,007 mm.

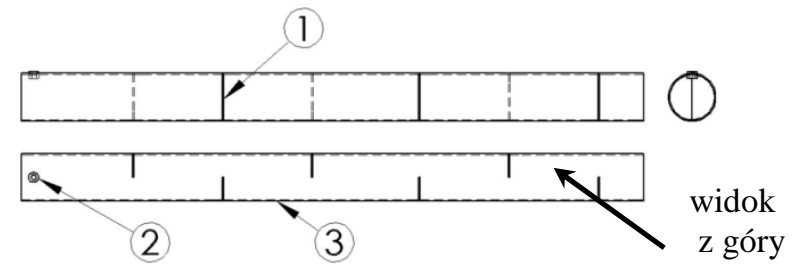

Rys. 1. Budowa mieszalnika: 1 - przegroda, 2 - króciec wlotowy kaolinu, 3 - korpus

Fig. 1. Design of the mixer: 1 - baffle, 2 - inlet tap of kaolin, 3 -body

Celem analizy i eksperymentu numerycznego jest ocena stopnia zmieszania kaolinu $\mathrm{z}$ wodą $\mathrm{w}$ poszczególnych sektorach mieszalnika oraz uzyskanie danych do optymalizacji kształtu i wielkości mieszalnika, w szczególności wielkości i ilości komór dzielonych przegrodami.

\section{Modelowanie CFD procesu mieszania}

W wykorzystywanym środowisku obliczeniowym ANSYS Fluent dostępnych jest kilka modeli symulacji przepływów wielofazowych, modele [1]: Vo- 
lume of Fluid (VoF), Mixture, Eulerian - Granular Multiphase Model oraz model Discrete Phase Modeling (DPM). Szczegółowa analiza [4] przydatności wymienionych modeli do symulacji zjawiska mieszania kaolinu z wodą pokazuje, że modele DPM oraz Eulerian jako najbardziej złożone, pozwalają na uwzględnienie w symulacji większości rzeczywistych zjawisk i procesów zachodzących podczas mieszania fazy stałej z fazą rozproszoną.

W modelu DPM dla fazy ciągłej są rozwiązywane równania zachowania wykorzystujące zmienne Eulera. Faza rozproszona jest natomiast potraktowana jako zestaw pojedynczych cząstek opisanych zmiennymi Lagrange'a. Ma to pozytywne konsekwencje w postaci bogatych możliwości modelowania dystrybucji wielkości cząstek [3], a negatywne np. w braku możliwości bezpośredniej oceny udziału fazy rozproszonej w fazie ciągłej. Model DPM pozwala np. śledzić trajektorię cząsteczek płynu.

Model Eulerian wykorzystuje zmienne Eulera do modelowania wszystkich faz. Pozwala jednocześnie na potraktowanie fazy rozproszonej jako strumienia granulowanych cząstek o jednakowej wielkości (średnicy).

$\mathrm{Z}$ racji tego, że badany układ stanowi mieszaninę cieczy i rozproszonych cząstek ciała stałego, czyli wody i kaolinu, przy określonym udziale masowym (objętościowym), do symulacji zastosowany został model Eulerian.

\subsection{Dobór metody badawczej}

Celem niniejszej pracy jest wyznaczenie wartości stopnia zmieszania w komorach mieszalnika, którą określić można dzięki statystycznym metodom zaproponowanym przez Hixsona i Tenneya [2,5]. Stopień zmieszania jest rozpatrywany w komorach pomiarowych od I do V, pokazanych na rysunku Rys. 2. Dla każdej komory wyznaczono dziewięć punktów pomiarowych, w których rejestrowane jest stężenie kaolinu.

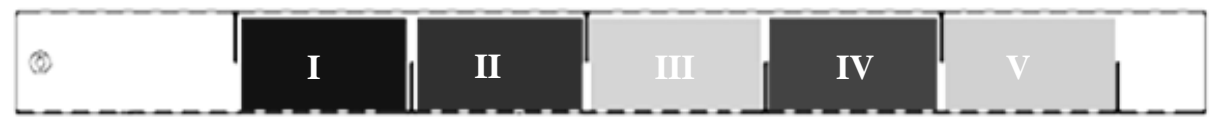

Rys. 2: Sektory pomiarowe mieszalnika

Fig. 2. Measuring zones of the mixer

Symulację przepływu ustalonego wykorzystano dla dobrania prawidłowych parametrów siatki obliczeniowej i modelu numerycznego przepływu. 


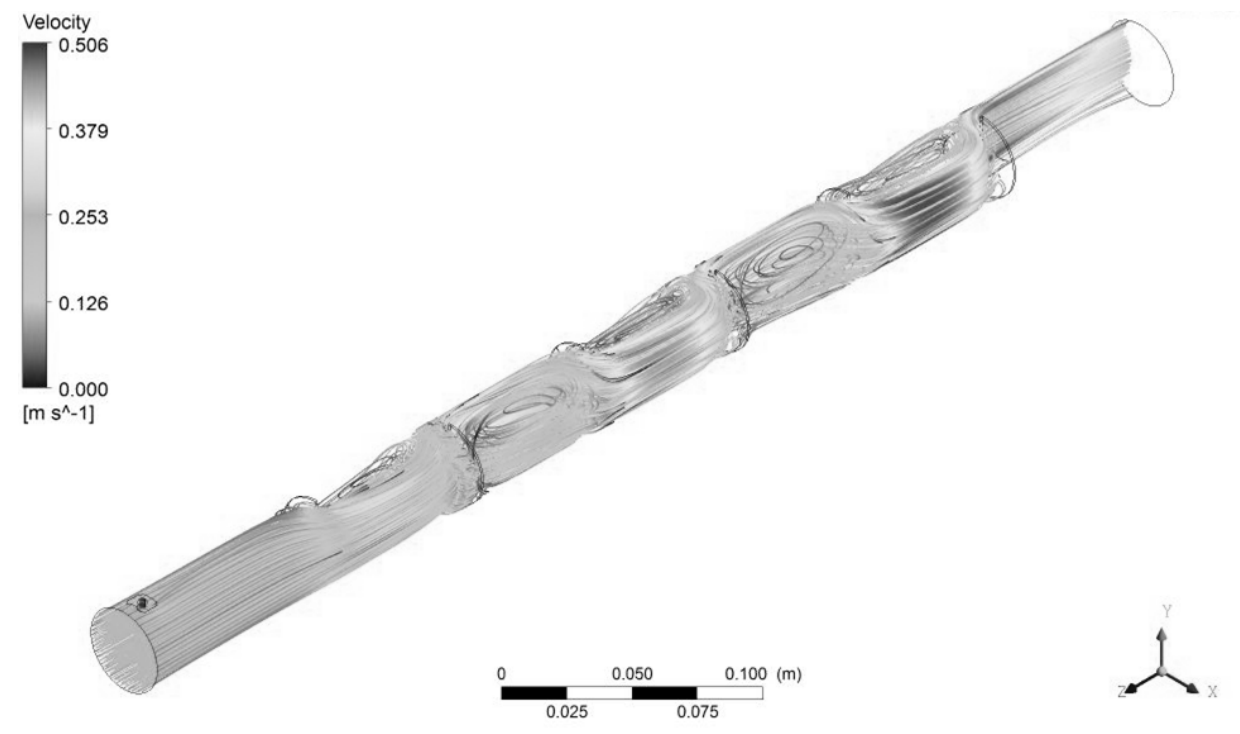

Rys. 3: Linie prądu według symulacji przepływu ustalonego

Fig. 3. Streamlines of the steady-state flow simulation

Dla określenia stopnia zmieszania oraz czasu niezbędnego do pełnego zmieszania wykonano symulacje nieustalonego procesu mieszania. Takie podejście, w porównaniu do symulacji procesu ustalonego, pozwala uzyskać znacznie więcej informacji o procesie. Można np. obserwować zmiany rozkładu rozproszonej fazy stałej na całej długości mieszalnika, a także określić minimalny czas mieszania. Krok czasowy przyjęty do obliczeń wynosi 0,001 s. Symulacje przeprowadzono dla dziesięciu sekund odliczanych od początku wprowadzania kaolinu do mieszalnika. W toku obliczeń wykazano, że przyjęty czas obliczeniowy jest wystarczający dla wyrównania i ustabilizowania procesu mieszania na całej długości mieszalnika. Wybrane istotne dane wejściowe i warunki brzegowe dla symulacji podano poniżej:

- Parametry kaolinu (faza dyskretna): - gęstość $2600 \mathrm{~kg} / \mathrm{m} 3$, lepkość zastępcza $1,72 \cdot 10-5 \mathrm{~kg} \cdot \mathrm{s} / \mathrm{m}$, średnica ziarna 1,0 10-6 m, zagęszczenie 0,67.

- Warunki brzegowe dla wlotu wody: strumień masy $0,1134 \mathrm{~kg} / \mathrm{s}$, średnica hydrauliczna 0,036 m, intensywność turbulencji 5,67\%,

- Warunki brzegowe dla wlotu kaolinu: - strumień masy $0,0005682 \mathrm{~kg} / \mathrm{s}$,

- Ściany: chropowatości 0,007 mm, interakcja ściany i kaolinu - odbicie.

Objętościowy stopień zmieszania $\Theta \mathrm{w}$ każdym punkcie pomiarowym oblicza się wg formuły:

$$
\Theta=\frac{v_{k}}{v_{k}+v_{w}}
$$


gdzie: $\mathrm{V}_{\mathrm{k}}$ - objętość kaolinu, $\mathrm{V}_{\mathrm{w}}$ - objętość wody.

Dla układu kaolin-woda o podanych parametrach, obliczeniowy stopień zmieszania w stanie ustalonym $\Theta=0,19$ [\%].

Zawartość kaolinu w mieszalniku wzrasta wprost proporcjonalnie przez okres około 3,5 sekundy od inicjacji jego podawania do mieszalnika, co określić można jako czas mieszania. Wykres zawartości masowej kaolinu w mieszalniku pokazano na wykresie Rys. 4.

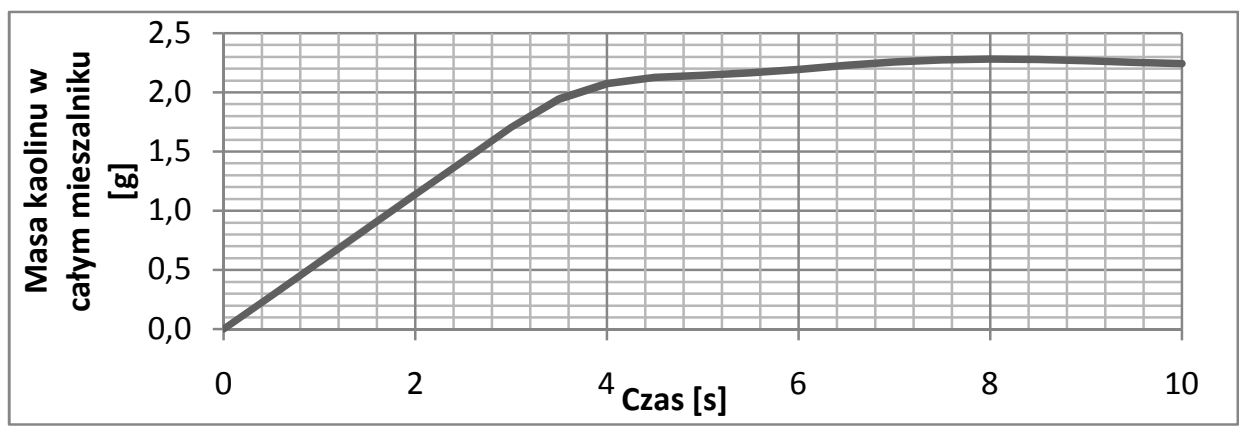

Rys. 4: Masa kaolinu w mieszalniku w funkcji czasu od początku jego podawania

Fig. 4. The mass of kaolin in the mixer as a function of the time from the start of its supply

Lekki wzrost masy kaolinu, wynoszący średnio $0,05 \mathrm{~g} / \mathrm{s}$ dla czasu powyżej 4 sekund świadczy o osadzaniu się pewnej ilości kaolinu w mieszalniku, co pokazano na rysunku Rys. 5. Ma to związek z jego gęstością, która jest prawie 2,6 razy większa od gęstości wody, efektem czego jest osadzanie się części ziaren na dnie mieszalnika. Zawartość kaolinu na dnie mieszalnika po upływie 10 sekund od rozpoczęcia mieszania wynosi około $0,04 \mathrm{~g}$, co dla danej chwili czasowej wynosi ponad 1,8 \% zawartości kaolinu w całym mieszalniku. Wyznaczony numerycznie stopień zmieszania kaolinu i wody w komorach w funkcji czasu pokazano na wykresie Rys. 6. Dane dla wartości I odpowiadają stopniowi zmieszania uzyskanemu w komorze I, pomiędzy pierwszą a drugą przegrodą. Kolejne numery krzywych na wykresie odpowiadają poszczególnym numerom komór. Uśredniając wyniki dla czasu z przedziału od 4 do 10 sekund uzyskano następujące wartości stopnia zmieszania: komora I - 0,125 $\%$, komora II - 0,185 \%, komora III - 0,200 \%, komora IV - 0,190 \%, komora $\mathrm{V}-0,167 \%$. Wymagany i zadowalający poziom stopnia zmieszania dla przepływu ustalonego uzyskuje się już w komorze II, w której średni stopień zmieszania wynosi $0,185 \%$. 


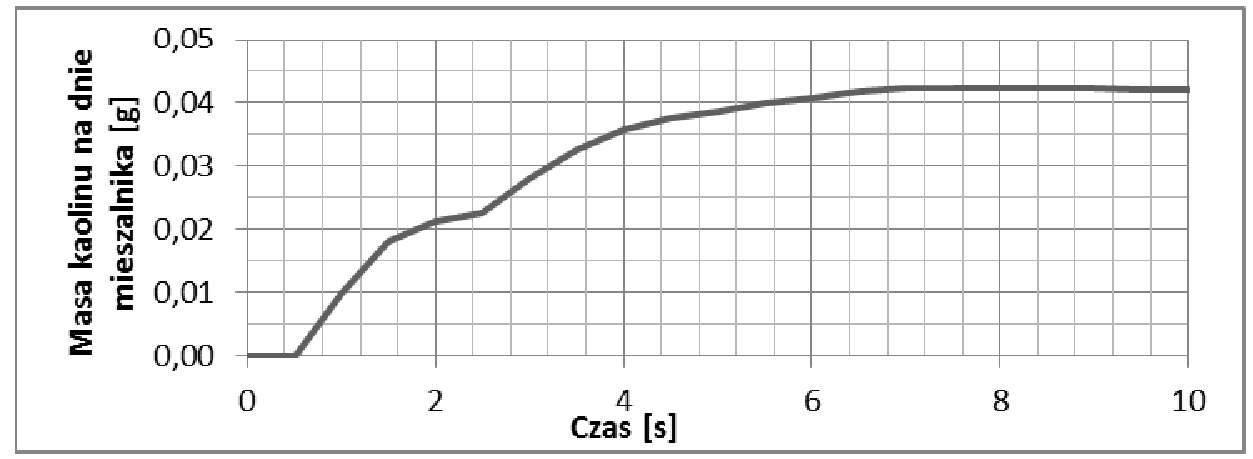

Rys. 5: Masa kaolinu na dnie mieszalnika w funkcji czasu od początku jego podawania

Fig. 5. The mass of kaolin in the mixer bottom as a function of the time from the start of its supply

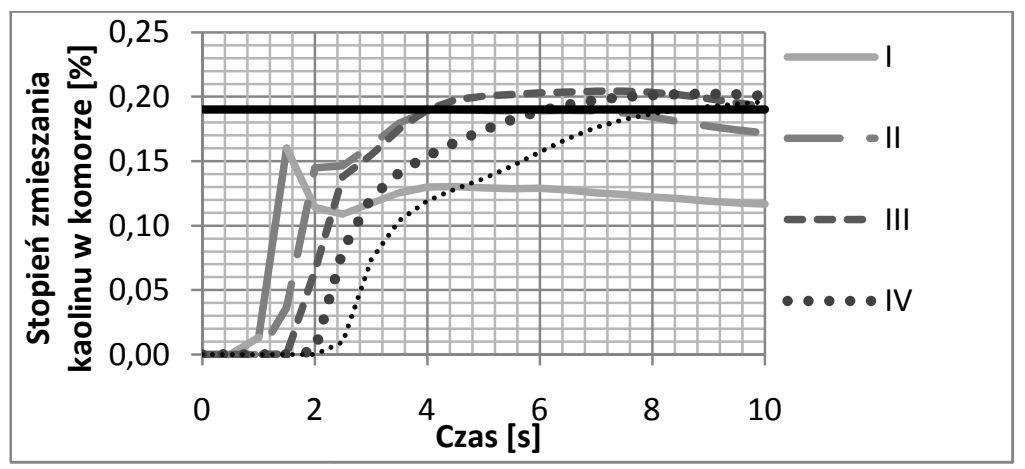

Rys. 6: Stopień zmieszania kaolinu w komorach

Fig. 6. The degree of mixing of kaolin in chambers

Ze względu na znacząco inną prędkość przepływu mieszaniny przez przewężenia na przegrodach (wyloty z komór) można spodziewać się nieco innego rozkładu zawartości kaolinu w wodzie. Na rysunku Rys. 7 przedstawiono stopień zmieszania kaolinu w obszarze przegród - na wylotach poszczególnych komór. Dane dla wartości I odpowiadają stopniowi zmieszania na wylocie z komory I, dla II - stopień zmieszania na wylocie z komory II, itd.

Wyniki uzyskane dla stopnia zmieszania na wylotach z komór są zbliżone do wyników uzyskanych dla komór. Zadowalający wynik stopnia zmieszania uzyskuje się na wylocie komory drugiej, dla którego średni wynik dla czasu ustalonego wynosi $0,183 \%$. Na wylocie komory trzeciej stopień zmieszania wynosi $0,199 \%$, czwartej $0,201 \%$, natomiast dla ostatniej $0,184 \%$. 


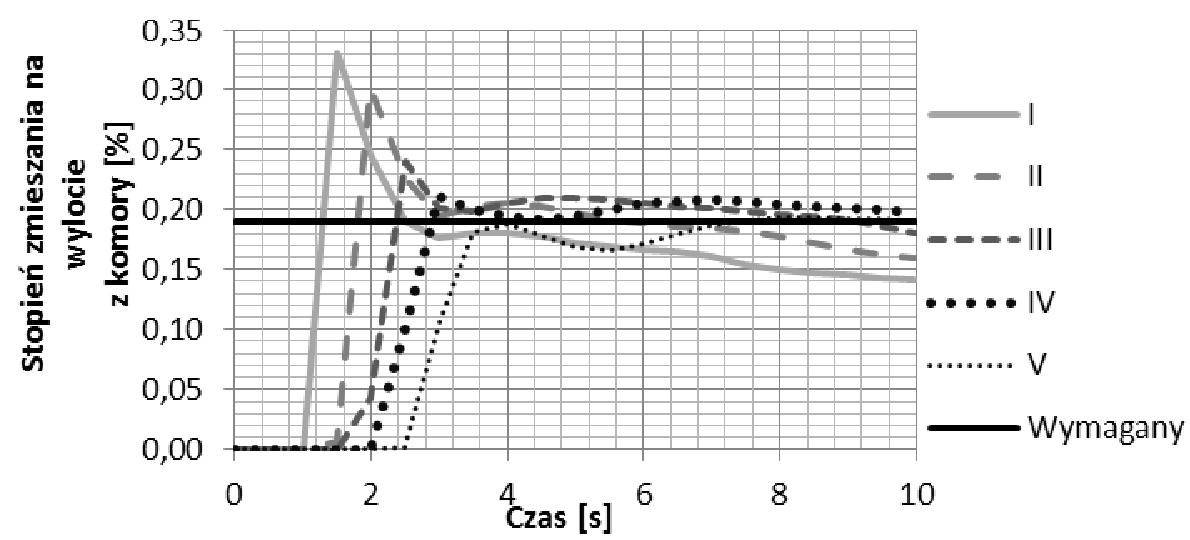

Rys. 7: Stopień zmieszania kaolinu na przegrodach - wylotach z komór

Fig. 7. The degree of mixing of kaolin on baffles - outlets from chambers

\section{Wnioski}

Analiza wyników symulacji procesu mieszania wody i drobin kaolinu pozwala osiągnąć kilka celów optymalizacyjnych. Mieszalnik według aktualnej konstrukcji spełnia założone wymagania projektowe, jednak wyniki symulacji pokazują, że bardzo dobry stopień zmieszania uzyskuje się już na poziomie drugiej komory, co pokazuje potencjał do zmniejszenia wielkości konstrukcji bez obniżenia jakości mieszania. Dodatkową korzyścią zmniejszenia ilości komór jest znaczące obniżenie oporów przepływu cieczy i strat ciśnienia przy przepływie przez mieszalnik. Proponowana optymalizacja konstrukcji powinna obejmować także różne warianty wielkości i kształtu przegród, przy czym funkcjami celu są w tym wypadku minimalizacja spadku ciśnienia i maksymalizacja stopnia zmieszania.

\section{Literatura}

[1] ANSYS FLUENT Documentation.

[2] Drew T. B., Hoope J. W.: Advances in chemical engineering, vol. 2, Academic Press Inc., New York 1958.

[3] Kantor R.: Analiza oddziaływania odolejacza sprężarki wyporowej w instalacji w warunkach przepływu ustalonego i pulsującego za pomocą CFD, Praca Doktorska, Politechnika Krakowska, Kraków 2004.

[4] Majoch M.: Wyznaczenie stopnia zmieszania wody i kaolinu w mieszalniku dynamicznym za pomocą CFD, praca magisterska, Politechnika Krakowska, Kraków 2012.

[5] Stręk F.: Mieszanie i Mieszalniki, WNT, Warszawa 1971. 
[6] Wójtowicz R., Szatko W.: Identyfikacja procesu powstawania flokuł w reaktorze, Inż. Ap. Chem., 51 (2012) 404-405.

\title{
NUMERICAL DETERMINATION OF THE DEGREE OF MIXING OF WATER AND KAOLIN IN THE STATIC MIXER
}

\begin{abstract}
S u m m a r y
Flocculation is one of industrial processes, being part of the process of water treatment. It is the process of formation of aggregates of solid particles, which are results of the binding interactions between aggregates through the adsorbed polymeric compound thereon. The resulting heavy and porous aggregates called floccules, begin to succumb to the force of gravity and are easy to filter. Flocculation process is initiated by the introduction of particles such as kaolin, which should be evenly distributed in the liquid phase. In the static mixer solid particles are introduced into the water or sewage directly before the mixer. The aim of the mixer is to ensure uniform distribution of solids particles within the liquid phase. In the present paper, the CFD simulations of the degree of mixing of water and kaolin in a static mixer and evaluation of its performance in terms of mixing efficiency and in an industrial usefulness are presented. Numerical simulations of transient process of the mixing process allow to model behavior of the solid particles along the entire length of the mixer, and as a result make it possible to determine the optimal dimensions of the mixer, such as, among others, its length and the number of baffles. This mixer can be used, among others, in the initial stages of sewage treatment or in production processes of suspensions.
\end{abstract}

Keywords: flocculation, suspensions, mixing, two-phase flow, CFD simulation, optimization

DOI: $10.7862 / \mathrm{rm} .2014 .41$

Otrzymano/received: 25.05 .2014

Zaakceptowano/accepted: 28.06 .2014 